\title{
A EDUCAÇÃO DE JOVENS E ADULTOS NO SÉCULO XXI - DA ALFABETIZAÇÃO AO ENSINO PROFISSIONAL*
}

\author{
Maria MARGarida MACHado, \\ da Universidade Federal de Goiás.
}

REsUmo: Este artigo apresenta uma análise da Educação de Jovens e Adultos, partindo das ações implementadas pelo governo federal para esta modalidade de ensino, no contexto da primeira década do Século XXI. O estudo prioriza o diálogo com ações direcionadas inicialmente para a alfabetização, especialmente o Programa Brasil Alfabetizado, chegando a ações voltadas para educação de jovens e adultos trabalhadores, com foco no Proeja no IFG em Goiânia. O indicativo da análise destas ações e programas é de que há uma ampliação do escopo de propostas para escolarização dos jovens e adultos, não se restringindo ou focalizando apenas em alfabetização, tendendo a buscar uma aproximação entre a educação básica e a educação profissional. Todavia, as iniciativas ainda não se constituem em política pública que envolva a população em larga escala, nem mesmo impactam uma visão, que está no senso comum, da pouca necessidade de escolarização dos jovens e adultos, revelando a falta de consciência da importância de uma cultura letrada no país e da educação como direito de todos.

Palavras-chave: Educação de jovens e adultos. Políticas nacionais. Educação profissional.

O Brasil concluiu a primeira década do novo século com um desafio ainda por superar: a baixa escolarização de sua população em geral e, em especial, das pessoas jovens e adultas. O tamanho deste desafio, segundo dados do Instituto Brasileiro de Geografia e Estatística, através da Pesquisa Nacional por Amostra de Domicílios (IBGE/Pnad, 2009) está, principalmente,

\footnotetext{
* Artigo recebido em 15/04/2011 e aprovado em 21/07/2011.
} 
entre os 134.985.990 brasileiros que possuem 18 anos e mais, representando $70 \%$ de toda a população. Destes jovens, adultos e idosos, 13.952 .579 não são alfabetizados e apenas 12.655.985 encontram-se matriculados em algum nível ou modalidade de ensino. Isto nos faz indagar por que o Brasil, chegando a $7^{\text {a }}$ economia, segundo dados do Produto Interno Bruto (PIB) mundial em 2011, não consegue mudar expressivamente este quadro de defasagem de escolarização? Por outro lado, o Índice de Desenvolvimento Humano (IDH) divulgado pela Organização das Nações Unidas e baseado na realidade dos países a partir principalmente do seu PIB per capita, da alfabetização, da escolarização, da expectativa de vida e natalidade, apresenta o Brasil em $70^{\circ}$ lugar do ranking de qualidade de vida, uma posição bastante incômoda comparada à do PIB mundial.

Esta questão não pode ser compreendida apenas por uma análise do que ocorre no interior da escola, nem por razões de ordem pessoal da população sem escolaridade. O problema da baixa escolaridade tem componentes históricos, que estão na raiz da constituição do Brasil enquanto nação, marcada pela lógica de um crescimento desigual e combinado, que tem como resultante uma riqueza imensa, concentrada ainda na mão de poucos e que não se distribui para a maioria que contribui diariamente com a sua produção. Portanto, a resposta à pergunta anterior pode ser a de que, para seguir o modelo de desenvolvimento econômico até o momento adotado pelo Brasil, a baixa escolaridade da população jovem e adulta não é negativa, ou, ainda, seria um dos elementos constituintes desta lógica.

A projeção do Brasil no cenário internacional como uma potência econômica emergente exige dos seus governantes, no entanto, medidas que demonstrem investimento no campo educacional, não apenas na elevação da escolaridade, mas na qualificação profissional em todos os níveis. Neste sentido, mesmo com a manutenção de condições de desigualdades sociais, pois não se trata de uma mudança radical no perfil socioeconômico da população, há necessidade de investimento em maior escolarização da população, em especial a economicamente ativa. Os dados da Pnad/2009 analisados pelo Instituto de Pesquisa Econômica Aplicada (Ipea), na publicação Comunicados do Ipea n. 66 (novembro de 2010), que trata dos avanços e problemas da educação brasileira, já evidenciam esta melhora em alguns indicadores, mas ressalva os desafios que ainda persistem, como a universalização da educação infantil e do ensino médio.

As reflexões aqui apresentadas buscam as evidências de mudanças ou não nos indicadores de escolarização da população jovem e adulta, no confronto com a análise das ações implementadas pelo governo brasileiro, com recorte mais específico no período de 2003 a 2010, partindo especial- 
mente das iniciativas de alfabetização e chegando às iniciativas de escolarização básica integrada à formação profissional inicial ou técnica. Para tanto, discute-se quem é o sujeito concreto que demanda esta escolarização, portanto, quem são os jovens e adultos não escolarizados no país. Em seguida, analisa-se a principal ação de alfabetização do Governo Lula, o Programa Brasil Alfabetizado (PBA), a partir dos dados disponibilizados no site oficial do MEC. Finalmente, dialoga com ações mais específicas de EJA induzidas pela esfera federal, com foco na experiência do Programa Nacional de Integração da Educação Profissional com a Educação Básica na Modalidade de Educação de Jovens e Adultos (Proeja) em Goiás. A análise dos programas buscou compreender suas implicações na configuração da educação de jovens e adultos como política pública.

\section{A INVISIBILIDADE DE UMA MAIORIA}

Para compreender um pouco melhor o desafio da baixa escolaridade da população brasileira, é necessário dialogar com os dados da Pnad/2009 analisados pelo Ipea (BRASIL, 2010, p. 6) sobre as médias de anos de estudos da população de 15 anos e mais, segundo categorias selecionadas que a caracterizam, tais como: o $1^{\circ}$ quinto (população mais pobre) e $5^{\circ}$ quinto (população mais rica), o recorte etário, o recorte étnico, o território urbano e rural e a comparação entre regiões. Embora esta publicação do Ipea chame a atenção para o que se pode considerar avanço, em comparação com os mesmos dados de anos anteriores, a análise que se segue busca destacar que o alcançado está longe de cumprir o preceito do direito à educação para todos assegurado na Constituição Federal de 1988.

Os dados da Pnad/2009 indicam que o $1^{\circ}$ quinto da população mais pobre do país apresenta média de 5,5 anos de estudos, comparado a 10,7 anos de estudos do $5^{\circ}$ quinto da população mais rica. Entre os jovens de 25 a 29 anos a média de estudos é de 9,4 anos, enquanto na população de 40 anos e mais a média de anos de estudos é de 6,2 anos. Do ponto de vista da diversidade étnico racial, negros possuem 6,7 anos de estudos em comparação a 8,4 anos de estudos dos brancos. Na área rural a média de anos de estudos é de 4,8 , ao passo que nas regiões metropolitanas os anos de estudos chegam a 8,7. Finalmente, ainda prevalecem significativas diferenças regionais, pois no Sudeste a média de estudos é de 8,2 anos e no Nordeste é 6,3 anos.

Várias reflexões decorrem dos dados apresentados acima. Eles revelam que a diferença de média de anos de estudos entre pobres e ricos ainda é a grande demonstração de como o acesso aos bens econômicos 
tem um forte impacto do acesso à instrução, embora os dados também informem que mesmo entre os mais ricos do país, a média de anos de estudos não equivale sequer à educação básica, que seria de onze anos de estudos completos. O desafio destes dados revela que o enfrentamento das desigualdades econômicas no país é fundamental para qualquer mudança significativa no acesso à educação, com a necessária permanência. Por outro lado, o enfrentamento da baixa escolaridade segue sendo um desafio de todos.

No que concerne à baixa escolarização da população de 40 anos e mais, que indica uma média inferior aos anos do ensino fundamental, cabe destacar que desde a Constituição Federal de 1988 o ensino fundamental passou a ser obrigatório, inclusive para os que a ele não tiveram acesso na chamada "idade própria". Portanto, nestes 22 anos da legislação em vigor, estes cidadãos, que à época da promulgação da lei tinham já 18 anos e mais, não tiveram seu direito de acesso e conclusão de oito anos de estudos garantido. É alarmante ainda a informação de que a média de anos de estudos entre os brasileiros de 25 a 29 anos é de apenas 9,4, pois estes eram crianças de 3 a 7 anos de idade no ano de 1988, quando da aprovação da Constituição Federal; no intercurso de 22 anos só alcançaram esta média tão baixa. Isto significa que mesmo na chamada "idade própria" nossas crianças não conseguem permanência e aprovação em fluxo adequado. Por outro lado, cabe ainda destacar que 9,4 anos de estudos, na realidade do ensino brasileiro, também não significa uma sólida formação, pois muitos dos mecanismos de promoção automática, correção de fluxo e aceleração de aprendizagem vem sendo utilizados, desde a década de 1990, mascarando a realidade de aprendizagem com a não reprovação, sem intervir de modo a garantir melhores condições de aprendizagem e trabalho nas escolas.

As três últimas categorias - questão étnica, relação campo e cidade e diferença regional - só confirmam a lógica desigual e combinada do nosso desenvolvimento econômico. Nossa frágil "democracia racial" ainda segue com uma diferença de 1,7 anos de estudos entre brancos e negros. As desigualdades de acesso, permanência e conclusão de estudos seguem presentes entre o campo e a cidade; a média de estudos no campo é quase a metade daquela encontrada nas regiões metropolitanas. Por fim, o Brasil, um país continental, segue reproduzindo as diferenças regionais com a permanência das regiões Norte e Nordeste com os piores índices educacionais, e ainda com dados deturpados, como por exemplo, os da Região Centro-Oeste que apresentam uma realidade quando considerados os Estados de Goiás, Mato Grosso e Mato Grosso do Sul, e outra bem diferente com a junção dos dados do Distrito Federal. 
As categorias analisadas acima revelam que o desafio da escolarização de jovens e adultos no Brasil passa pelo enfrentamento de vários condicionantes históricos que produziram um país desigual. A educação pode e deve ser um dos elementos de busca da superação destas condições; todavia, não há qualquer chance de mudança nesta realidade sem o enfrentamento das desigualdades econômicas e sociais que seguem sendo produzidas. Neste sentido, o discurso feito em torno da defesa de uma escolarização de jovens e adultos, seja em ações de alfabetização ou realizadas no âmbito do nível médio e profissionalizante, revela-se mero discurso, pois o modelo econômico ainda vigente no país não"precisa" destes trabalhadores escolarizados. Chega a ser contraditório o alarde de que não há mão de obra qualificada no Brasil, quando assistimos a disputa diária por um emprego formal pelos jovens e adultos de nível técnico e superior. O que então está reservado, nesta lógica de mercado, para os não alfabetizados ou sem educação básica?

No Brasil há décadas as mudanças econômicas do país se utilizam de discursos favoráveis à expansão do acesso aos estudos. Este argumento acompanha as justificativas de ações históricas que marcaram o atendimento escolar da população jovem e adulta em âmbito nacional. Nas iniciativas federais de alfabetização, sempre entendidas como ações que se desenvolveriam por meio de parcerias, podem ser destacadas as campanhas de alfabetização, a partir da criação do Serviço de Educação de Adultos em 1947, que perduraram até o inicio dos anos 1960; o Movimento Brasileiro de Alfabetização (Mobral), principal política de alfabetização do período da Ditadura Militar (1967-1985); o Programa Alfabetização Solidária (PAS) no Governo de Fernando Henrique Cardoso (1996-2002); e o Programa Brasil Alfabetizado que teve início em 2003, no Governo Lula, e segue como programa de alfabetização no atual Governo Dilma.

Das iniciativas federais vinculadas à educação profissional, o movimento histórico evidencia a constituição de duas redes paralelas de oferta desta formação para os trabalhadores, uma que nasce como instituição pública e outra pela concessão do poder público ao setor empresarial. No setor público destaca-se a criação, pelo Decreto n. 7.566, de 23 de setembro de 1909, de um sistema escolar de aprendizes artífices; que se transformará, em 1959, na Rede Federal de Ensino Técnico; passando na década de 1990 para Centros Federais de Educação Profissional e Tecnológica, chegando atualmente aos Institutos Federais de Educação, Ciência e Tecnologia, com a Lei n. 11.892/2008. Ainda no setor público, a Lei n. 5.692/71 reforma o ensino secundário transformando-o em $2^{\circ}$ grau profissionalizante, embora esta compulsoriedade tenha tido pouco efeito prático, resultando em sua extinção pelo Decreto 7.044/82. Com a nova legislação retorna a oferta de cursos de 
caráter exclusivamente propedêutico nas escolas estaduais, observando-se pouquíssimas experiências expressivas de educação profissional de nível técnico nestas redes.

Ainda na educação profissional, como concessões do Estado ao setor empresarial, em 1942 é criado o Serviço Nacional de Aprendizagem dos Industriários (Senai) pelo Decreto-Lei n. 4.048 e, em 1946, o Serviço Nacional de Aprendizagem Comercial (Senac), pelo Decreto-Lei n. 8.621. Essas Instituições vieram a constituir o que se conheceria posteriormente como "Sistema S", com inúmeras escolas profissionalizantes, sob a coordenação das confederações patronais dos mais diversos campos do trabalho, num entrelaçamento de interesses políticos e benefícios indiretos e diretos no uso de recursos públicos.

Essas experiências históricas no campo da alfabetização e educação profissional chegam ao século XXI nas configurações assumidas pelos programas implementados no Governo Lula, dos quais cabe analisar a proposição, a implementação e o significado, na tentativa de compreendê-los como constituintes e constitutivos da lógica de manutenção ou não da desescolarização da população jovem e adulta, em face dos interesses do modelo de desenvolvimento econômico do país.

\section{A ALFABETIZAÇÃO DE JOVENS E ADULTOS - AINDA UM PROGRAMA}

O Programa Brasil Alfabetizado (PBA), ${ }_{1}^{1}$ criado pelo Decreto n. 4.834, de 8 de setembro de 2003, é uma ação do Ministério da Educação que convoca uma mobilização nacional para atuar no campo da alfabetização de jovens e adultos. $O$ programa prevê repasse de recursos financeiros às instituições parceiras para pagamento de bolsa a alfabetizadores e coordenadores de turmas; formação inicial e continuada dos alfabetizadores; ajuda de custo para material escolar, transporte e alimentação dos alfabetizandos; material didático de alfabetização através do Programa Nacional do Livro Didático para Alfabetização de Jovens e Adultos. A oficialização do PBA se dá por via da publicação de uma resolução do $\mathrm{MEC}$, estabelecendo os critérios de participação dos parceiros, que devem aderir ao Sistema Brasil Alfabetizado (SBA).

As informações básicas de como se dá o atendimento nas classes de alfabetização são acompanhadas pelos dados fornecidos pelos parceiros do PBA ao MEC. O SBA é um sistema de dados que armazena os Planos Plurianuais de Alfabetização (PPAlfa) que precisam ser elaborados e enviados pelos parceiros do programa; registra nominalmente os dados de alfabetizandos, alfabetizadores, turmas e coordenadores de turmas que existem em todo o 
país. Por este sistema é possível gerar informações como a série histórica de idade dos jovens e adultos que frequentam o programa desde 2003.

Tabela 1 - Alfabetizandos por faixas etárias nos anos de 2003 a 2009*

\begin{tabular}{|c|r|r|r|r|r|r|r|}
\hline Idade & \multicolumn{1}{|c|}{2003} & \multicolumn{1}{c|}{2004} & \multicolumn{1}{c|}{$\mathbf{2 0 0 5}$} & \multicolumn{1}{c|}{$\mathbf{2 0 0 6}$} & \multicolumn{1}{c|}{$\mathbf{2 0 0 7}$} & \multicolumn{1}{c|}{$\mathbf{2 0 0 8}$} & \multicolumn{1}{c|}{2009} \\
\hline 15 a 17 & 0 & 0 & 0 & 0 & 6.698 & 14.729 & 16.948 \\
\hline 18 a 29 & 237.257 & 212.068 & 345.812 & 331.841 & 258.750 & 267.555 & 241.384 \\
\hline 30 a 45 & 645.549 & 532.753 & 792.751 & 710.225 & 569.554 & 560.777 & 488.361 \\
\hline 46 a 60 & 497.150 & 402.131 & 604.264 & 539.805 & 434.246 & 431.254 & 372.608 \\
\hline 61 a 90 & 308.948 & 261.501 & 396.118 & 352.193 & 268.163 & 259.784 & 234.385 \\
\hline 91 a 119 & 8.499 & 3.909 & 5.483 & 5.265 & 2.616 & 2.334 & 2.119 \\
\hline Total & 1.697 .403 & 1.412 .362 & 2.144 .428 & 1.939 .329 & 1.540 .027 & 1.536 .433 & 1.355 .805 \\
\hline
\end{tabular}

Fonte: Sistema Brasil Alfabetizado - 2003 a 2009

* Os dados de 2003 a 2009 foram disponibilizados em relatório da Secad em dezembro de 2009. Em 2010 o mesmo sistema apresenta os dados por faixa etária, mas com recortes diferentes, que buscamos agregar do modo mais próximo possível dos dados anteriores: 15 a 19 anos - 39.275 alfabetizandos; 20 a 29 anos 216.287 alfabetizandos; 30 a 44 anos $-469.137 ; 45$ a 59 anos $-401.346 ; 60$ a 79 anos -261.332 alfabetizandos; acima de 80 anos - 26.927 alfabetizandos; num total de 1.403 .218 alfabetizandos.

Estas informações geradas a partir do SBA são uma fonte riquíssima de avaliação do programa, pois possibilitam uma série de indagações, tais como: por que o crescimento de jovens no programa a partir de 2007? Como explicar a presença de tantos idosos acima de 90 anos? Ou, ainda, o decréscimo do número de alfabetizandos a partir de 2005 significaria o atendimento da demanda? O que se pode depreender destes dados sobre o atendimento é a distância ainda existente entre a cobertura do programa e a demanda para alfabetização de jovens e adultos existente no país, que, como já mencionado, é de 13.952.579 para a população de 18 anos e mais. Pouco mais de $10 \%$ do público-alvo é atendido, menos ainda se considerarmos os dados de analfabetismo de 15 anos e mais. Outra análise que preocupa é a efetivação do processo de alfabetização, pois a implementação de campanhas e programas tem revelado que a continuidade dos estudos é fator preponderante para a aquisição real do letramento. Quem garantirá esta continuidade? Esta indagação nos leva a tentar compreender quem realiza o programa, como pode ser observado na Tabela 2.

Observa-se a mudança no perfil das parcerias estabelecidas pelo PBA, desde seu início, em 2003, até o ano de 2010, quando o financiamento deixa de ser repassado por convênios com outras instituições que não sejam as redes públicas de ensino, o que vai ocorrer a partir do ano de 2007. Esta opção pela transferência dos recursos às instituições públicas é justificada pelo governo como uma tentativa de atender ao preceito constitucional de obrigatoriedade do Estado na implementação da política de educação. 
Todavia, isso não significa impedimento às secretarias estaduais e municipais de firmarem convênios com organizações não governamentais ou setores empresariais para a execução do programa nas localidades, o que continuou ocorrendo.

Tabela 2 - Parceiros do PBA nos anos de 2003 e 2010

\begin{tabular}{|l|c|c|}
\hline Parceiros & 2003 & 2010 \\
\hline Secretarias de Educação Estaduais e Municipais & $44 \%$ & $100 \%$ \\
\hline $\begin{array}{l}\text { Organizações Não Governamentais (incluindo área } \\
\text { empresarial) }\end{array}$ & $53 \%$ & $0 \%$ \\
\hline Instituições de Ensino Superior & $3 \%$ & $0 \%$ \\
\hline
\end{tabular}

Fonte: Sistema Brasil Alfabetizado

Um outro dado que chama a atenção no SBA é a crescente participação dos municípios de forma mais autônoma e direta. Nos primeiros anos do programa, a maioria das parcerias firmadas eram feitas pelas secretarias estaduais, que depois realizavam convênios com os municípios para execução das ações de alfabetização. Os dados do SBA relativos ao ano de 2010 indicam que 20 secretarias estaduais firmaram parceria com o PBA e 1.423 secretarias municipais, totalizando 1.443 parceiros. Todavia, a cobertura em termos de número de alfabetizandos atendidos é maior na parceria das secretarias estaduais, que somam 793.642 do total de 1.403.218 alfabetizandos, enquanto os municípios respondem por 615.708 alfabetizandos.

Um número maior de alfabetizandos nas iniciativas de secretarias estaduais (57\%) é preocupante, pois de acordo com as leis educacionais brasileiras a ação dos estados da federação é prioritária no ensino médio e apenas complementar no ensino fundamental. Assim, esses estados possivelmente não devem priorizar a oferta do primeiro segmento do ensino fundamental para os egressos do PBA. Esta deve ser uma obrigação dos municípios, que tem assumido na última década esta matrícula, embora em proporções que não representam a expansão esperada para o atendimento a todos os que passam pelos programas de alfabetização; ao contrário, a matrícula de EJA nos anos iniciais do ensino fundamental e nos demais segmentos tem decrescido, como confirmam os dados da Tabela 3.

As perguntas que decorrem dos dados oficiais do programa passam inicialmente por uma avaliação da pertinência do PBA. Questão já presente no próprio governo quando elaborou, através da Diretoria de Políticas da Educação de Jovens e Adultos (Dpeja), da Diretoria de Diversidade e Inclusão Educacional e da Diretoria de Estudos e Acompanhamento das Vulnerabilidades Educacionais (Deave), o Plano de Avaliação do PBA. O plano, 
Tabela 3 - Jovens e adultos em ações de alfabetização, ensino fundamental e médio de EJA

\begin{tabular}{|c|c|c|c|c|}
\hline Ano & $\begin{array}{c}\text { Brasil } \\
\text { Alfabetizado }\end{array}$ & $\begin{array}{c}\text { EJA Fundamental } \\
\text { - Anos iniciais }\end{array}$ & $\begin{array}{c}\text { EJA Fundamental } \\
\text { - Anos Finais }\end{array}$ & $\begin{array}{c}\text { EJA - Ensino } \\
\text { Médio }\end{array}$ \\
\hline 2004 & 1.412 .362 & 1.530 .275 & 1.812 .637 & 988.746 \\
\hline 2005 & 2.144 .428 & 1.466 .329 & 1.861 .424 & 1.073 .694 \\
\hline 2006 & 1.939 .329 & 1.472 .188 & 1.989 .948 & 1.219 .438 \\
\hline 2007 & 1.540 .027 & 1.160 .879 & 2.206 .153 & 1.608 .559 \\
\hline 2008 & 1.536 .433 & 1.127 .077 & 2.164 .187 & 1.635 .245 \\
\hline 2009 & 1.355 .805 & 1.035 .610 & 2.055 .286 & 1.547 .275 \\
\hline 2010 & 1.403 .218 & 923.197 & 1.922 .907 & 1.388 .852 \\
\hline
\end{tabular}

Fonte: SBA/Secad/MEC e Censo da Educação Básica/INEP/MEC

desde seu início, indicava a necessidade de ações de acompanhamento, monitoramento e avaliação de suas ações, o que efetivamente demandariam a participação de várias instituições ligadas à pesquisa institucional e, em especial, à avaliação em educação. ${ }^{2}$ A Secretaria de Educação Continuada, Alfabetização, Diversidade (Secad) apresenta assim o sentido destas ações que se deram em função do Plano de Avaliação do PBA:

Um processo contínuo e amplo de avaliação requer a realização de avaliações de naturezas diversas em momentos diferentes. A seguir, argumentamos que uma ampla avaliação do Programa Brasil Alfabetizado deve contemplar a realização de 36 avaliações específicas, que formam o Mapa de Avaliações. A qualidade e pertinência, e daí a utilidade, das diversas avaliações depende, sobremaneira, da existência de um rico sistema integrado de informações sobre o funcionamento e desempenho do programa. (HENRIQUES; BARROS; AZEVEDO, 2006, p. 37-38).

Um registro importante desta experiência brasileira de avaliação de um programa de alfabetização está publicado na Coleção Educação Para Todos, ${ }^{3}$ numa Série intitulada Avaliação, dedicada ao Plano de Avaliação do Programa Brasil Alfabetizado, composta por cinco livros. Deste amplo processo de avaliação dois aspectos devem ser aqui destacados: primeiro, o da mobilização de recursos para a ação de alfabetização e, segundo, o da eficácia do programa. Ambos podem ser avaliados pelos próprios dados disponíveis no SBA. Quanto à mobilização dos recursos, os dados oficiais disponíveis no portal do MEC (http://pde.mec.gov.br, acessado em 12 de dezembro de 2009) indicavam um aumento de investimento federal no PBA, que se inicia em 2003, da ordem de 193 milhões, chegando a 315 milhões no 
ano de 2007. O Plano de Avaliação do PBA tem buscado identificar até que ponto o aumento de recursos tem resultado numa melhora dos resultados finais do processo de alfabetização. Ou seja, além do volume é necessário avaliar a sustentabilidade e adequabilidade do programa.

O sucesso de um programa social depende, em última instância, do volume de recursos com que pode contar e de sua efetividade em traduzir recursos em resultados. A disponibilidade de recursos é tão importante quanto a efetividade. Mesmo que o programa seja extremamente efetivo, isto é, mesmo que para cada real gasto seja gerado o maior impacto possível sobre a vida dos beneficiários, o impacto total do programa ainda dependerá do volume de recursos utilizado. Logo, o êxito de um programa está condicionado à interação entre a disponibilidade de recursos e sua efetividade. (HENRIQUES et al, 2006, p. 47).

A avaliação do uso dos recursos traz, em relação à política de alfabetização, questionamentos tais como: em que medida a aumento do recurso investido pelo governo federal tem contribuído para desestimular os demais entes públicos, secretarias estaduais e municipais, a continuarem seus investimentos próprios na ação de alfabetização? Como garantir que as ações de alfabetização tenham continuidade após as mudanças de governo, tendo em vista que o fim do analfabetismo não está diretamente vinculado aos mandatos políticos? E, ainda, como garantir que o investimento feito corresponda ao cumprimento das metas previstas, com a eficiência que se espera do PBA? No Plano de Avaliação do PBA os seis primeiros instrumentos utilizados tentam dar respostas a estas questões.

No segundo aspecto, que se refere à eficácia do PBA, está posto o desafio de avaliar o resultado concreto do processo de alfabetização no que concerne à aquisição de habilidades de leitura, escrita e numerização por parte dos alfabetizandos e, ainda, avaliar a continuidade de estudos dos jovens e adultos que passam pelo PBA. Os testes cognitivos aplicados nas turmas de alfabetização, no início do processo e no final, indicam dados importantes para o redesenho do programa, como, por exemplo, a existência nas turmas de um número considerável de pessoas já alfabetizadas desde o início do processo. Isto nos leva a indagar por que estas pessoas retornam às classes de alfabetização? Seria esta a única oferta de escolaridade nos locais onde residem? Onde há outras turmas de EJA qual a justificativa para a permanência em classes de alfabetização?

Estas questões nos fazem voltar à Tabela 3 e verificar que algo de errado está presente nesta estratégia de alfabetização, já que o desafio da continuidade dos estudos, que é complexo, não vem se efetivando. As 
dúvidas diante dos resultados do Censo Escolar do INEP são muitas. A expectativa em face dos investimentos feitos de 2003 a 2010 era exatamente de um resultado contrário a este, pois há maior aporte de recursos, há mais formação de alfabetizadores, há efetivação de ações de suporte às classes de alfabetização (alimentação, transporte, material didático), há um plano de avaliação e acompanhamento dessas ações. Com tudo isso, os alunos não prosseguem os estudos, ou, pelo menos, não prosseguem na quantidade esperada, impactando o aumento da matrícula registrado no sistema de EJA.

Uma das variáveis explicativas desse fato, que está sendo apontada pela avaliação de eficácia do PBA, corresponde à baixa expectativa de continuidade de estudos dos alfabetizandos, principalmente entre os idosos acima de 61 anos de idade, que somavam 17\% dos matriculados no PBA em 2008. Esses alunos alegavam buscar as habilidades de leitura e escrita apenas para realização pessoal e contribuição em atividades cotidianas, como reconhecer o itinerário do transporte coletivo ou ainda ler a Bíblia. Essa baixa expectativa também se observava entre os adultos que possuem entre 46 e 60 anos, que correspondiam a $28 \%$ do matriculados no PBA, cujos argumentos para o não prosseguimento nos estudos já começavam a identificar a ineficiência de uma certificação de escolaridade na disputa por vaga no mercado de trabalho, já que esta faixa etária se encontra fora da considerada População Economicamente Ativa (PEA).

A baixa motivação pessoal para a busca pela continuidade nos estudos, todavia, não é suficiente para explicar o mesmo fenômeno acontecendo entre os jovens de 15 a 29 anos, ou, ainda, entre os adultos entre 30 e 45 anos de idade. Em parte, o Plano de Avaliação do PBA também identifica os indicadores socioeconômicos dos sujeitos envolvidos no PBA como limitadores da continuidade do processo de escolarização. Em especial, a necessidade de sobrevivência, a busca pelo trabalho precarizado, a mobilidade de moradia, são condições reais que limitam a população demandante das classes de alfabetização a prosseguir em seus estudos. $O$ enfrentamento desses fatores limitantes faz com que se retome um dos elementos-chave para o sucesso de qualquer política de Educação de Jovens e Adultos, que se chama intersetorialidade. Não há ações de alfabetização e educação de jovens e adultos que alcancem eficácia se não forem acompanhadas de políticas intersetoriais, envolvendo programas de saúde, geração de renda, fixação de moradia, segurança para acesso às escolas, transporte que facilite a chegada à escola, entre outras. 


\section{A EJA E SUA INDUÇÃO FEDERAL - MAIS UMA VEZ POR MEIO DE PROGRAMAS}

A marca mais significativa no imaginário social da população brasileira, quando nos referimos à educação de jovens e adultos, ainda é seu tratamento como alfabetização, por consequência do peso histórico das experiências relacionadas ao Mobral ou ao ensino supletivo. Consequentemente, há também neste imaginário a ideia de que se fala de um resíduo de adultos e idosos, que não se escolarizaram por motivos pessoais e, provavelmente, não mais o farão. Como já evidenciado no início deste texto, a realidade não é bem esta. Nem estes sujeitos da EJA são residuais, nem cabe mais na realidade atual pensar que a reedição de experiências como o Mobral e o supletivo sejam suficientes para enfrentar o problema da baixa escolarização da população jovem e adulta do país. Partindo desta percepção, é necessário, então, dizer de que EJA se está falando no início do século XXI, o que a indução efetivada pelo governo federal, pela via do financiamento, contribui com a oficialização ou não da modalidade e qual sua relação com a educação profissional.

A educação de jovens e adultos passa a ser considerada uma modalidade de ensino a partir da Lei n. 9.394/96 e esta concepção se fortalece com a aprovação, pelo Conselho Nacional de Educação, do Parecer n. 11/2000 e da Resolução n. 1/2000 que tratam das Diretrizes Curriculares para Educação de Jovens e Adultos. Todavia, isso não representou mudança radical na realidade das escolas que ainda seguem uma compreensão da EJA pautada na experiência da suplência, ou seja, na oferta de escolarização aligeirada e compensatória. Mais grave ainda, a oficialização da modalidade não representou um maior compromisso dos estados e municípios com a oferta de ensino fundamental e médio voltados à especificidade destes jovens e adultos.

A existência de um programa de apoio financeiro às matrículas da educação de jovens e adultos em âmbito federal (até 2002, conhecido por Recomeço, depois de 2003 passando a ser chamado de Fazendo Escola e, posteriormente, PEJA até sua extinção em 2007) revela que há dificuldades desta modalidade em se manter pelas iniciativas exclusivas dos estados e municípios. Essa dificuldade se intensificou desde a implantação da Lei n. 9.424 que em 1996 criou o Fundo de Manutenção e Desenvolvimento do Ensino Fundamental e Valorização do Magistério (Fundef), ${ }^{4}$ cujos vetos impediam a contagem dos alunos matriculados em EJA para a distribuição dos recursos que seriam investidos no ensino fundamental. Os impactos destes vetos podem ser observados por dois movimentos diferenciados: por um lado, o de ajustes feitos pelos gestores públicos para não perderem recursos, podendo-se tomar como exemplo claro desse caso o Estado da Bahia, 
que passa a contar os alunos de EJA como classes de aceleração, as quais poderiam ser computadas para o repasse dos recursos do fundo; por outro, o de reivindicação, pois as dificuldades de manutenção de matrículas em EJA fizeram com que governadores das Regiões Norte e Nordeste cobrassem do governo federal uma solução; a resposta a essa demanda foi a criação do Programa Recomeço.

A principal função do programa era a complementação de recursos para que os gestores municipais e estaduais não fechassem as classes de educação de jovens e adultos do ensino fundamental que não poderiam ser beneficiadas com os recursos do Fundef. O fato de o programa ter sido criado para apoio quase exclusivo às regiões norte e nordeste do país criou uma cisão em termos da política educacional: de um lado os estados e municípios que, tendo matrículas em EJA, mas não se enquadrando nos critérios do programa não receberiam recursos e, portanto, tinham de se manter sem apoio do governo federal; de outro lado, estados e municípios beneficiários do programa, que passam a depender da chegada do recurso para manter a oferta de EJA, ou seja, aquilo que era para constituir apoio para ampliar a oferta vira condição para abertura das classes de EJA.

O Programa Recomeço sofreu mudanças a partir de 2003, passando a ser nomeado Programa Fazendo Escola, mas sua essência, o incentivo à matrícula na EJA por meio da descentralização de recursos, não foi alterada, exceto quanto a sua cobertura. A Resolução CD/FNDE n. 25, de 16 de junho de 2005, deixa de fazer distinção de estados e municípios por índice de desenvolvimento humano (IDH), passando a universalizar o apoio a todos que têm matrícula em EJA. Essa Resolução também indica uma aproximação entre matrículas da EJA e alunos potencialmente mobilizados pelas turmas de alfabetização do Programa Brasil Alfabetizado (PBA). O repasse de recursos da União para os estados e municípios é feito mediante a publicação de uma resolução que orienta a execução do Programa Fazendo Escola, que passa a ser conhecido pela sigla PEJA.

O PEJA teve uma existência curta, pois desde 2006 dá-se início a um processo de transição da política de financiamento do governo federal, que cria o Fundo de Manutenção e Desenvolvimento da Educação Básica e de Valorização dos Profissionais da Educação (Fundeb) pela Emenda Constitucional n. 53/2006, regulamentado pela Lei n. 11.494/2007 e pelo Decreto n. 6.253/2007, em substituição ao Fundef, que vigorou de 1997 a 2006. O Fundeb vai incorporar a matrícula da EJA na contabilização dos recursos, o que resulta na extinção do PEJA, pois a compreensão do governo 
federal é de que esta inclusão já representa o apoio aos sistemas estaduais e municipais na manutenção e ampliação das matrículas de jovens e adultos.

A implantação do Fundeb a partir de 2007 não elimina, todavia, outras ações financiadas pelo governo federal no campo da EJA, as quais já vinham sendo implementadas desde o início do Governo Lula. Um desses programas está focado na integração da educação profissional com a educação básica na modalidade de EJA, o Proeja; outro é dirigido exclusivamente aos jovens que não concluíram o ensino fundamental, numa perspectiva de inclusão, o Projovem Urbano. O principal interesse neste artigo é descortinar, um pouco mais, o quanto essas ações de EJA, aproximadas da educação profissional, colaboram ou não com a institucionalização da EJA como política pública de Estado. Para tanto, as reflexões aqui apresentadas partem especialmente da realidade do Proeja em Goiânia, tomada como base para algumas indagações sobre a política de EJA em âmbito nacional.

Os programas no campo da EJA criados pelo Governo Lula, a partir de 2003, foram sofrendo várias alterações no decorrer de seu primeiro mandato. No caso do Proeja, a principal mudança foi sua ampliação da oferta, pois o Decreto n. 5.478 de 2005, que cria o Programa no âmbito da rede federal de educação profissional e tecnológica, foi substituído pelo Decreto n. 5.840 de 2006, ampliando a apoio do governo federal à implementação do Proeja também para as redes estaduais e municipais.

\section{O PROEJA EM GOIÂNIA NA SUA CONFIGURAÇÃO FEDERAL}

Em Goiânia, o Proeja ${ }^{5}$ passa a ser ofertado em 2006 pelo Centro Federal de Educação Tecnológica (Cefet/GO), atual Instituto Federal de Educação Ciência e Tecnologia de Goiás (IFG), através do curso Técnico em Serviço de Alimentação, denominado Curso Técnico em Cozinha, a partir de 2008. O Proeja na rede estadual de ensino tem sua oferta iniciada a partir de 2009, com o curso de Assistente Administrativo, no formato concomitante, pois os alunos frequentavam duas escolas: quatro dias estudavam no Centro de Educação de Jovens e Adultos (CEJA) do Setor Universitário e um dia frequentavam aula no Centro de Educação Profissional Sebastião Siqueira (CEPSS) em outro bairro, distante $12 \mathrm{~km}$ do primeiro. Ainda no Município de Goiânia, numa oferta em parceria entre a Secretaria Municipal de Educação e o IFG, teve início em 2010 a primeira experiência de Proeja-FIC, ou seja, formação inicial e continuada de trabalhadores integrada ao ensino fundamental, num curso de Alimentos. As três experiências revelam questões instigantes para a análise das implicações de um programa no seu potencial ou não 
de fortalecimento da EJA como política pública. Neste artigo as reflexões apresentadas tratam da experiência de implantação do Proeja no IFG.

O Proeja no IFG foi cercado por um conjunto de ações coordenadas para o acompanhamento da implementação do programa. O curso Técnico Integrado em Serviços de Alimentação teve início em agosto de 2006, com a matrícula de 25 alunos. No mesmo ano, o IFG, em parceria com outras instituições de ensino superior, sob a coordenação da Faculdade de Educação da Universidade Federal de Goiás (FE/UFG), passou a contar com financiamento para pesquisa, por um edital da CAPES específico para acompanhar as ações de Proeja. ${ }^{6}$ Ainda em 2006, a Setec/MEC lançou um edital para oferta de cursos de pós-graduação Lato Sensu, com foco na formação de professores para atuar no Proeja, sendo que o IFG participou numa primeira experiência como polo do Cefet/MG, e elaborou um projeto próprio7 em 2007, em parceria com a FE/UFG.

Analisando este conjunto de iniciativas, pode-se ressaltar que as seleções semestrais para entrada de alunos no Proeja do IFG Campus Goiânia contou com uma oscilação em termos de demanda. Como na primeira seleção não houve aprovados para completar uma turma, foram matriculados todos os 25 que buscaram o curso. A partir desta primeira experiência, o IFG buscou ampliar a divulgação do curso, contando com a parceria do Fórum Goiano de Educação de Jovens e Adultos, o que mobilizou um número bem expressivo de jovens e adultos interessados. Todavia, a existência de um único curso de Proeja, dentro do IFG Campus Goiânia, como vem ocorrendo de 2006 até 2011, contribuiu para manter a invisibilidade dessa modalidade dentro da instituição. Inúmeras dificuldades na manutenção de um curso voltado para jovens e adultos trabalhadores já foram discutidas no IFG, por meio de seminários denominados Diálogos Proeja; de reuniões entre os professores que atuam no curso; de reuniões entre os pesquisadores do IFG e da FE/UFG; de atividades formativas como palestras e cursos. No Plano de Desenvolvimento Institucional (PDI - 2010-2014), documento em debate no site oficial do IFG, há indicação de quatro novos cursos de Proeja a partir de 2012, o que se torna fundamental para a sobrevivência da modalidade de EJA dentro de uma instituição de excelência em formação profissional, mas que, todavia, tem dificuldades em lidar com alunos efetivamente trabalhadores, de baixa renda e com escolaridade defasada.

A pesquisa que vem sendo realizada desde 2007, financiada pela Capes, para acompanhar a implantação do Proeja em Goiás, desdobra-se em várias pesquisas. À medida que a equipe inicial de pesquisadores foi se aproximando do desafio da implantação do Proeja, diversos temas de 
pesquisa foram sendo agregados: a gestão local e nacional do programa (temas de duas professoras do IFG, hoje doutorandas da FE/UFG); a formação dos professores que atuam no Proeja (tema de três pesquisas de iniciação científica); a questão do sujeito jovem no Proeja e na EJA (tema de uma tese de doutorado e uma de mestrado); a implantação do Proeja pela Secretaria de Estado da Educação - Seduc/GO (tema de duas dissertações de mestrado); outros temas correlatos, como a questão da EJA e Proeja no sistema prisional, entre mulheres e com jovens na interação com o ambiente virtual multimídia (todos objeto de investigação em dissertações de mestrado).

Essa significativa produção no campo da Educação e Trabalho e da EJA acabou por fortalecer a temática no Programa de Pós-Graduação em Educação (PPGE) e na FE/UFG, em especial no diálogo para a reconstituição da Linha Educação, Trabalho e Movimentos Sociais. Outro aspecto a ser evidenciado foi o fortalecimento do grupo de estudos e pesquisas envolvido com a temática da EJA na FE/UFG. Esta mesma avaliação não pode ser feita no interior do IFG, onde o tema do Proeja, do ponto de vista da pesquisa, ainda é pouco reconhecido, haja vista que nem a conquista de um Doutorado Interinstitucional (Dinter) entre UFG/IFG, na área da educação, com doutoranda investigando o Proeja, tem sido suficiente para garantir um investimento da instituição nesta temática.

No que concerne à formação dos professores do IFG para atuar em Proeja, uma avaliação da oferta do curso de especialização pela parceria IFG/ UFG destaca o pouco envolvimento dos professores do IFG nesta iniciativa enquanto alunos. O Curso destinava-se a um público específico de professores das redes públicas de ensino que atuavam em educação de jovens e adultos e/ou educação profissional, nos âmbitos federais, estaduais e municipais. Este objetivo foi alcançado apenas em parte, porque a presença de professores da rede federal foi insignificante no universo dos alunos do curso (menos de $10 \%$ do total de alunos matriculados). A maioria dos professores era da rede estadual de educação de Goiás e das redes municipais de Goiânia, Aparecida de Goiânia, Bonfinópolis. Os professores do IFG alegaram não ter interesse por pós-graduação lato sensu, pois vários já possuem mestrado e doutorado.

O Curso de Especialização teve início com 95 alunos, foram montadas 3 turmas, funcionando uma no IFG Campus Jataí, uma no IFG Campus Goiânia e uma na Faculdade de Educação. Destes 95 alunos, 66 concluíram as dez disciplinas do curso e 47 defenderam as monografias e foram aprovados no final do curso, dos quais apenas 3 são professores do IFG. As 47 monografias produzidas encontram-se disponíveis para acesso no site http://www. forumeja.org.br/pf/node/186. Os motivos de desistência entre os alunos que 
iniciaram o curso e não concluíram as disciplinas foram levantados e assim resumidos: falta de tempo para se dedicarem a um curso que tinha muitas leituras e atividades propostas; desmotivação no decorrer do curso, pois o fato de já ter outra especialização significava não ter mais retorno financeiro com o título a ser adquirido; problemas de saúde dos próprios professores-alunos ou de familiares que dependiam diretamente deles, entre outros.

As dificuldades apresentadas pelos professores-alunos do curso de especialização também foram motivo de discussão nas reuniões de planejamento que ocorreram mensalmente com os professores do curso. Uma série de estratégias pedagógicas foram traçadas para auxiliar na permanência e participação dos alunos, sem o prejuízo da qualidade e do rigor que o curso se propôs a manter. Todavia, dentre tantas outras, uma questão básica a ser levada em consideração na oferta de novos cursos com este perfil se ressaltou: é quase impossível manter um bom nível de curso, pensando numa formação rigorosa e numa participação efetiva dos professores-alunos, quando eles trabalham três turnos diários, como era o caso da maioria dos que estavam fazendo o curso. Isso indica a necessidade de liberação destes profissionais em tempo parcial, para que se dediquem às leituras, à pesquisa e às demais atividades que uma formação como esta demanda.

O peso da carga horária de trabalho na instituição, todavia, não estava presente entre o corpo docente do IFG, pois este já possui carga horária de ensino reduzida, se comparada à dos demais professores da rede estadual e municipal. Todavia, nem isso os levou a priorizar a participação no curso. O que se pode perceber de ponto positivo nesta iniciativa de formação foi a atuação de professores do IFG como professores das disciplinas do curso. Das dez disciplinas do curso, quatro foram ministradas por eles, que assumiram também a orientação das monografias finais do curso. Dos quatro professores envolvidos, duas estão fazendo o doutorado na FE/UFG em pesquisas que envolvem a temática do Proeja. Este envolvimento também se efetivou na participação de outros três professores do IFG no grupo de pesquisa constituído a partir das pesquisas de Proeja, coordenadas pela FE/UFG.

\section{DESAFIOS NA CONSTITUIÇÃO DA EJA COMO POLÍTICA PÚBLICA}

O que observamos em relação às duas experiências analisadas programa de alfabetização e programa de EJA integrada à educação profissional - é que as iniciativas ainda não se constituem em política pública que envolva a população em larga escala, nem mesmo interferem na superação de uma visão que está no senso comum, da pouca necessidade de escolarização dos jovens e adultos. Essa constatação revela a falta de 
consciência da importância de uma cultura letrada no país e da educação como direito de todos. Há uma ampliação do escopo das propostas de escolarização dos jovens e adultos, que não se restringem mais apenas à alfabetização, tendendo a buscar uma aproximação entre a educação básica e a educação profissional; todavia, não se altera a posição marginal da EJA no conjunto das políticas educacionais.

As ações aqui analisadas resultam de indução do governo federal, através de repasses diretos aos entes federados. Esse fomento, pela via de programas que apoiam ações de alfabetização e EJA, está sujeito a atrasos e dificuldades nos trâmites burocráticos entre o ministério e as instituições parceiras. Assim, não são ações que se incorporam facilmente à rotina diária das instituições, o que causa a paralisação das ofertas de atendimento quando falta o recurso federal. Este fato contribui para a perpetuação da ideia de que ações voltadas à escolarização de jovens e adultos são sempre temporárias e descontínuas.

Por outro lado, as repetidas ações descontínuas afetam também a forma como a sociedade brasileira percebe a educação para jovens e adultos trabalhadores. De um lado, há quem a entenda como direito, que deve ser garantido nos mesmos padrões de qualidade da educação ofertada às crianças e adolescentes, considerando suas especificidades pedagógicas - este é, por exemplo, o posicionamento do movimento dos Fóruns de EJA do Brasil. Por outro lado, ainda persiste em parte significativa da população brasileira uma visão de que a EJA é o lugar de aligeirar o acesso ao conhecimento e à certificação, numa visão conformista de que qualquer certificado em menor tempo é melhor do que nenhum.

Portanto, para além das políticas de Estado que precisam estar articuladas em torno de programas de alfabetização e educação básica com formação profissional para jovens e adultos, há que se considerar a necessidade também de uma mudança de "cultura", ou melhor, de concepção da sociedade brasileira no que concerne à percepção e valorização da educação como um todo. A trajetória histórica de uma educação voltada para a elite e de outra destinada aos pobres, que marca a realidade brasileira, precisa ser alterada, ou permaneceremos com uma parte significativa da população ainda achando que já passou da idade de estudar, que a educação já não faz sentido nas suas vidas; ou, por outro lado, vamos legitimar uma concepção de educação utilitarista, segundo a qual só faz sentido a educação escolar que imediatamente prepara para algo. Como se aprender não fosse um direito de todos e um processo que se desenvolve ao longo de toda a vida (Brasil, 1998). 
EDUCATION OF YOUNG PEOPLE AND ADULTS INTHE XXI CENTURY - FROM LITERACY TO VOCATIONAL EDUCATION

ABSTRACT: This article presents an analysis of Youth and Adult Education, based on Federal Government measures for this type of education in the context of the first decade of the twenty-first century. The study focuses on dialogue with the proposed action initially aimed at promoting literacy, especially the Brazil Literate Program, and moves on to the education of youth and adult workers, with particular emphasis on PROEJA at the Instituto Federal de Goiás in Goiânia. The analysis of these actions and programs would indicate that there has been a broadening of the scope of proposals for the education of young people and adults. It is no longer restricted or focused only on literacy, but tends to bring basic and vocational education closer together. However, the initiatives have not yet become public policies involving people on a large scale, nor have they been any way influential in trying to get rid of a very commonly held view that young people and adults have little need of education. This reveals the country's lack of awareness of the importance of the right of all to culture and education.

KEY WORDS: Education of youth and adults. National policies. Vocational education.

\section{NOTAS}

1. Para a apresentação de dados do PBA a autora contou, em 2009, com a disponibilização de dados dos sistemas informatizados da Secretaria de Educação Continuada Alfabetização e Diversidade do Ministério da Educação, pelo então Diretor de EJA Jorge Teles. Os dados de 2010 foram obtidos no site http://portal.mec.gov.br/index. php? Itemid=86\&id=12280\&option=com_content\&view=article.

2. Desde 2005 quando o Plano de Avaliação do PBA teve seu início, a Secad contou com várias instituições: Instituto de Pesquisa Econômica Aplicada (IPEA); Centro de Alfabetização, Leitura e Escrita (Ceale/UFMG); Sociedade Científica da Escola Nacional das Ciências Estatísticas (Science/ENCE); Associação Nacional dos Centros de Pós-Graduação em Economia (Anpec); e Instituto Paulo Montenegro (IPM/lbope); Universidade de Brasília (UNB).

3. Para conhecer acesse em domínio público no portal do MEC ou ainda no endereço http://forumeja.org.br/colecaoparatodos. Dessa coleção até 2010, encontramos 12 livros que tratam especificamente de temas relacionados ao campo da Educação de Jovens e Adultos.

4. O Fundef estabeleceu regras e critérios para o gerenciamento dos recursos que devem ser aplicados por estados e municípios no Ensino Fundamental em todo o território nacional. Este fundo administrava $15 \%$ dos $25 \%$ de recursos que são obrigatoriamente vinculados à educação. 
5. No site http://www.forumeja.org.br/pf/node/187 estão disponíveis dissertações já defendidas que abordam a experiência do Proeja no IFG e na Seduc/GO.

6. O Programa de Pós-Graduação da FE/UFG encaminhou, para concorrer ao Edital n. 03/2006 Proeja-Capes/Setec, o projeto em parceria com o IFG, a UnB e a PUC-Goiás, intitulado "O Proeja indicando a reconfiguração do campo da Educação de Jovens e Adultos com qualificação profissional - desafios e possibilidades". Os resultados deste projeto encontram-se disponíveis no site: http://www.forumeja.org.br/pf/node/18.

7. O Projeto de curso da especialização em Proeja, bem como as produções dos alunos, encontram-se disponíveis no site http://www.forumeja.org.br/pf/node/5.

\section{REFERÊNCIAS}

BRASIL. V Conferência Internacional sobre Educação de Adultos. Hamburgo, julho 97. Brasília: MEC, 1998.

. Ministério do Planejamento. Secretaria de Assuntos Estratégicos. Instituto de Pesquisa Econômica Aplicada. Comunicados do IPEA. PNAD 2009 - Primeiras análises: situação da educação brasileira - avanços e problemas, n. 66, 18 de novembro de 2010. HENRIQUES, Ricardo; BARROS, Ricardo Paes de; AZEVEDO, João Pedro (Orgs). Brasil alfabetizado: caminhos da avaliação. Brasília: MEC- Secretaria de Educação Continuada, Alfabetização e Diversidade, 2006. 216 p. (Coleção Educação para Todos, Série Avaliação, n. 1, v. 18).

Instituto Brasileiro de Geografia e Estatística (IBGE). Pesquisa Nacional por Amostra de Domicílio (Pnad). Instituto Nacional de Estudos e Pesquisas Educacionais Anísio Teixeira. Censo Escolar. 2009.

www.forumeja.org.br/colecaoparatodos

www.forumeja.org.br/pf

www.mec.gov.br

Maria MARGarida MACHAdo é Professora Doutora em Educação pela PUC-SP. Atua como docente da Faculdade de Educação da Universidade Federal de Goiás e está vinculada ao Programa de Pós-Graduação em Educação. É membro do Grupo de Pesquisa "Estado e Políticas Educacionais", onde investiga sobre Educação de Jovens e Adultos, Educação Profissional, política de educação municipal.

Email:mmm2404@smail.com 